\title{
O Aplicativo Uber é uma tendência nas pequenas cidades como nova opção de Mobilidade Urbana
}

\author{
José Suélio Ferreira ${ }^{l}$; Mariene Amorim Alves ${ }^{1}$; Mayara Lima Aquino ${ }^{1}$ : Luzia Coelho Rodrigues ${ }^{2}$; \\ Francisco Ricardo Duarte ${ }^{3}$
}

Resumo: O presente estudo situou o contexto da temática mobilidade urbana, com o objetivo de identificar as implicações de possível implantação do aplicativo UBER na cidade de Juazeiro-BA, bem como suas contribuições para o usuário em relação ao serviço de táxi. Para tanto, utilizou-se a coleta de dados com proprietários e usuários dos serviços de transporte de uso individual, modalidades táxi e mototáxi. Os dados coletados foram analisados quantitativamente. Resultados indicam, a partir da percepção dos respondentes, a existência de pouco conhecimento sobre o aplicativo UBER, mas sugestivos de resistência por parte de taxistas. Os demais grupos pesquisados demonstraram interesse pela nova modalidade de transporte urbano. Para desdobramento da pesquisa, sugere-se a inclusão de outros grupos de interesse, a exemplo de gestores públicos em pesquisas futuras.

Palavras-chave: Mobilidade urbana, Meios de transporte, Aplicativo UBER, percepção de usuários.

\section{The Uber application is a trend in small cities as a new Urban Mobility option}

\begin{abstract}
The present study placed on the context of urban mobility, in order to identify the implications of the possible implementation of the UBER application in the city of Juazeiro-BA, as well the contributions to the user in relation to the taxi service. For this purpose, the data collection was used with owners and users of transportation services for individual use, modalities taxi and motorcycle. The collected data were analyzed quantitatively. The results indicate, from the perception of the respondents, the existence of little knowledge about the UBER application, but suggestive of resistance by taxi drivers. The other groups studied showed an interest in the new modality of urban transport. In order to unfold the research, it is suggested to include other interest groups, such as public managers in future research.
\end{abstract}

Keywords: Urban mobility, Means of transportation, UBER application, user perception.

\section{Introdução}

A cidade de Juazeiro, município baiano, é servida por meio de transporte de uso coletivo e de uso individual. No entanto, esses serviços vêm sendo alvo de reclamações, na mídia, por parte da população de Juazeiro- BA, em relação ao atendimento inadequado ao usuário.

\footnotetext{
1 Graduação em Administração Pública (em andamento) pela Universidade Federal do Vale do São Francisco (Univasf). Contatos: josesuelio@yahoo.com.br; marienne2@hotmail.com; Mayaralima20@hotmail.com.

${ }^{2}$ Mestra em Administração (UFBA); licenciatura Plena em Letras; especialista em Capacitação Pedagógica de Professores. Docente do Bacharelado em Administração Pública EAD da UNIVASF. Contato: luzia.coelho@univasf.edu.br.

${ }^{3}$ Doutor em Difusão do Conhecimento (UFBA); mestre em Administração; graduação em Administração e em Filosofia. Professor Adjunto da Fundação Universidade Federal do Vale do São Francisco. Contato: frduarte0@ gmail.com 
Essa reclamação recorrente, em relação à mobilidade urbana, aponta alguns fatores: o ônibus transporte mais barato e que atende a maior parte da população, não chega a todos os bairros da cidade; o serviço de táxi tem várias limitações: o custo é alto e atende apenas uma pequena parte da população, geralmente, com percursos entre residência e rodoviária, supermercado e residência; os motos taxis são mais populares, porém limitado: apesar do custo razoável, nem todos está disposto a usar o meio de transporte, pois não oferece a segurança adequada aos usuários (OLMOS; FAVERA, 2016).

Há outro meio de locomoção urbana existente, que ainda não está implantado em todas as cidades, mas surge com a proposta de oferecer conforto, qualidade e segurança e que poderá ser alternativa de transporte público para a cidade de Juazeiro. Nesse sentido, o aplicativo UBER, motivo de muitas discussões no mundo inteiro, e, principalmente, nas grandes cidades brasileiras tem causado um reboliço entre os taxistas que veem nesse novo aplicativo um grande concorrente e uma possibilidade concreta de superação no atendimento aos usuários (OLMOS; FAVERA, 2015; GOMIDE, 2008).

O taxi é antigo e tradicional e durante muitos anos tem dominado esse segmento de transporte individual, mas, recentemente, teve a sua hegemonia ameaçada pelo Moto Táxi, que depois de muitas disputas judiciais de muitas passeatas reivindicações para serem legalizado ou reconhecido como um transporte viável, em várias capitais brasileiras, inclusive no interior, foi regulamentado e adotado em algumas cidades como mais uma opção de transporte individual, mesmo que o seu custo seja, em alguns casos, superior ao taxi tradicional. O moto taxi é um meio de transporte utilizado por muitos, e devido ao seu custo razoável e principalmente rapidez na locomoção, convive atualmente, lado a lado com taxistas sem problemas mais sérios.

A mobilidade urbana é assunto discutido no mundo inteiro, as populações aumentaram em níveis exponenciais e as autoridades políticas não promoveram o desenvolvimento das cidades nas mesmas proporções, ou seja, as obras estruturantes das cidades estão em defasagem em relação ao crescimento populacional.

Dessa forma, novas opções de meios de transportes são criadas com o objetivo de atender a essa nova demanda populacional. Há, na verdade, vários especialistas trabalhando incansavelmente procurando novas opções de transportes não apenas para atender à demanda excedente, mas, principalmente, para forçar até certo ponto, os proprietários de veículos 
particulares a adotarem o sistema de transporte público, seja de uso individual como os taxis, ou coletivo, como os ônibus, BRT's, etc. Mesmo com todas essas alternativas existentes, novas opções estão surgindo e outras ressurgindo, como os trens e metrôs (GOMIDE, 2008).

Como uma nova alternativa de transporte urbano, o UBER vem surgindo em meio a muitas polêmicas e discussões nas capitais mundiais e principalmente no Brasil. O aplicativo tem sido uma nova alternativa de mobilidade urbana com alguns diferenciais em relação aos demais sistemas de transportes urbanos. Porém, como todo novo sistema de transporte urbano não desenvolvido pelas autoridades públicas, o sistema UBER tem causado debates em todos os sentidos sociais, políticos e jurídicos. Esse aplicativo tem vantagens e desvantagens para os proprietários dos veículos, desde o custo de funcionamento do sistema, assim como os diferenciais de qualidade adotados em relação ao modelo tradicional de taxi.

Neste estudo, procurou-se decorrer sobre o funcionamento do aplicativo UBER, vantagens e desvantagens para os proprietários e usuários, além de destacar algumas exigências do sistema para manter a qualidade do serviço. Sendo assim, o objetivo foi identificar as implicações de possível implantação do sistema UBER na cidade de JuazeiroBA e suas contribuições para o usuário em relação ao serviço de táxi.

Para o desenvolvimento do estudo, buscou-se a literatura sobre Mobilidade Urbana, uma vez que é atual a discussão sobre a temática, objetivando integrar os diferentes modos de transporte e melhorar a acessibilidade e a mobilidade das pessoas e cargas, sendo instituídas, nesse sentido, no Brasil, as diretrizes da Política Nacional de Mobilidade Urbana (BRASIL, 2012).

\section{Mobilidade Urbana e deus Desafios}

No Brasil a grande transformação na mobilidade das pessoas começou a ocorrer em 1950, quando o processo intenso de urbanização se associou ao número de uso de veículos motorizados, a exemplo dos carros e dos ônibus (IPEA, 2016). A questão de excesso de veículos motorizados nas grandes cidades vem se agravando, nas últimas décadas, devido à concentração de pessoas na cidade e à falta de planejamento urbano. 
Paralelamente a isso, o transporte público brasileiro sempre foi motivo para muitas reclamações ao longo dos anos. As manifestações, muitas vezes, são referentes à falta desse transporte, que acarreta superlotação nos horários de pico, e às condições dos equipamentos utilizados, demonstrando baixa qualidade do serviço prestado e falta de segurança ao passageiro. No ônibus, por exemplo, principal meio de transporte para deslocamento, no Brasil (IPEA, 2016) somente o motorista tem acesso ao cinto de segurança. A situação agrava-se diante da cobrança de tarifas elevadas para a qualidade dos serviços prestados (GOMIDE; CARVALHO, 2016).

Diante da concentração de pessoas nos centros urbanos e da dificuldade de acesso ao trabalho e aos serviços públicos de qualidade, transportes privados a exemplo de automóvel e motocicleta passam a assumir posição importante para a população (VASCONCELLOS, 2016). Esses fatores influenciam a mobilidade das pessoas. Para o autor, as principais características individuais e sociais dessa influência são: idade, condição física, gênero, escolaridade e renda pessoal ou familiar.

Para Vasconcellos (2015), a renda contribui para a diminuição da mobilidade a pé, tendo como consequência o aumento rápido da mobilidade por automóvel. Além disso, outras características da família, tais como idade e número de filhos interferem nas necessidades de deslocamento. Sendo assim, fica evidente a necessidade de refletir sobre as condições de mobilidade urbana e, consequentemente, discutir políticas públicas para o setor. Portanto, é de suma importância levar em consideração a análise sobre a política de investimentos em transporte público, adaptando-o e assegurando o seu acesso à população, multiplicando os modais de transporte público para além dos ônibus, como por exemplos o aumente de instalações de metrôs, trens e ciclovias, uma vez que os usuários escolhem a modalidade de transporte de acordo com o custo e o tempo de percurso (VASCONCELLOS, 2015).

Nesse sentido, Gomide (2008, p.12), afirma que mobilizações sociais "contra os aumentos de tarifas dos ônibus urbanos ocorridas em 2003 em várias cidades brasileiras, sob a forma de protestos de estudantes" despertaram a atenção de políticos por questões ligadas ao transporte urbano.

No Brasil, foi promulgada, em 2012, a Lei Federal 12.587 que prevê na elaboração do Plano Diretor dos municípios com mais de 20.000 habitantes a elaboração do Plano de Mobilidade Urbana, objetivando melhorar a acessibilidade e a mobilidade das pessoas e 
cargas e integrar os diversos meios de transporte dos municípios (FREITAS NETO et al., 2017). Concomitantemente, fala-se em mobilidade sustentável, surgindo inclusive, alternativas tecnológicas para o transporte urbano, a exemplo do aplicativo UBER.

\section{Funcionamento do aplicativo Uber e diferenças em relação ao Serviço de Táxi}

O UBER, como aplicativo de celular, emergiu no contexto da economia compartilhada (sharing economy), nos Estados Unidos, em 2009, já sendo utilizado em mais de 500 cidades no mundo, em mais de 67 países, surgindo como inovação nas modalidades de transporte e atingindo o uso em grande escala (VIEGAS; LETRA, 2016). Por meio do uso do aplicativo, os usuários encontram rapidamente motoristas particulares, que atuam como empreendedores individuais, credenciados na plataforma UBER. $O$ aplicativo tornou-se atrativo diante do acesso simples e da eficiência dos serviços prestados, o que desperta, no usuário, uma sensação de atendimento diferenciado.

No Brasil, a empresa chegou em 2014. Essa entrada trouxe consigo diversos questionamentos sobre a (i)legalidade do serviço prestado pelos motoristas particulares para a sociedade, surgindo questionamentos quanto à legitimidade da atividade profissional no ordenamento jurídico do país, surgindo ocorrências de confusões entre taxistas e motoristas do UBER (VIEGAS; LETRA, 2016; NUNES, 2015). De acordo com Nunes (2015), os conflitos foram gerados em todas as cidades atendidas pelo aplicativo. Assim, os taxistas veem a prática como uma concorrência desleal e não merecedora do apoio do poder público, uma vez que os motoristas credenciados, na plataforma UBER, não são submetidos à tarifação tributária e ganham espaço cada vez mais no mercado. A autora assim descreve:

\footnotetext{
Dessa forma, ao tentar repassar ao passageiro maior sensação de segurança e conforto, a Uber vem fortemente se popularizando, no Brasil e no mundo, como alternativa ao transporte público, sendo merecedora, desta forma, do olhar do Direito sob todas as relações jurídicas que por ventura possam estar envolvidas com o tema, eis que a cada dia que passa os cadastros da empresa aumentam (NUNES, 2015, p.11).
}

Dessa forma, a UBER é um aplicativo disponível para celulares que conecta motorista a passageiros, oferecendo um serviço de transporte semelhante ao taxi. Para acessar o 
serviço, o passageiro preciso instalar o aplicativo móvel e fazer o cadastro. O pagamento pode ser pelo cartão de crédito. No Brasil, a empresa já funciona no Rio de Janeiro, São Paulo, Belo Horizonte, Brasília, Campinas, Goiânia, Porto Alegre, Guarulhos, Curitiba e Recife.

Essa inovação vem revolucionar o mercado de transportes de passageiros, com modalidades e tarifas diversas, a exemplo do UberX, que possui tarifa econômica, e o UberBLACK com carros padronizados. Segundo Olmos e Fávera (2015), UBER e Taxistas oferecem serviços distintos. Os autores apresentaram quadro comparativo, desenvolvido pelo site G1, para esclarecer diferenças de serviços e custos entre as modalidades de transporte.

Essas diferenças incluem tipo de veículo, custo, bandeira utilizada, utilização da tarifa, taxa de retorno: a Uber exige carros fabricados a partir de 2010, com padrão de conforto, exigência não expressa para os táxis. As bandeiras UberBLACK (luxo) e UberX ( categoria econômica) funcionam com valores mais baixos que a tarifa comum do taxi (MELLO; DANTAS, 2015; OLMOS; FAVERA, 2015). Além disso, a facilidade de uso do aplicativo vem revolucionando o mercado de transportes de passageiros nas grandes cidades, possibilitando, inclusive, a localização automática do chamado, o que possibilita identificar, com rapidez, o motorista mais próximo. Acrescenta-se, ainda, a possibilidade de dividir viagem sem custo adicional em função de o custo ser valor fixo.

Apesar do amplo alcance, a inovação ainda não se consolidou em todas as cidades brasileiras (MELLO; DANTAS, 2015), mas já preocupa taxistas e empresas tradicionais do serviço de táxi. Diante disso, este estudo situou a temática, buscando identificar a percepção de taxistas, mototaxistas e usuários em relação à possível implantação do serviço UBER na cidade de Juazeiro-BA, localidade ainda não alcançada pelo serviço em referência.

\section{Metodologia}

A pesquisa é de natureza quantitativa, de caráter descritivo (MARCONI; LAKATOS, 2010) e exploratório, quanto aos seus fins, pois visa conhecer a opinião de taxistas, moto taxistas e usuários sobre o uso do aplicativo UBER na cidade de Juazeiro-BA. Inicialmente, realizou-se uma pesquisa documental para a obtenção de informações sobre o UBER e para 
subsidiar a elaboração do questionário, instrumento aplicado diretamente, pelos pesquisadores, no período de 01 de novembro de 2016 a 28 de fevereiro de 2017.

O instrumento foi composto de perguntas estruturadas sobre o aplicativo e suas funcionalidades, com respostas do tipo "sim", "não" e "não sei". Foram incluídos como sujeitos de pesquisa grupos de interesse pela modalidade de transporte individual a exemplos de taxistas, mototaxistas e usuários diversos. Sendo assim, os sujeitos de pesquisa foram: 70 taxistas, 360 mototaxistas, amostra não probabilística, porém significativa para o universo de taxistas (125) e mototaxistas (700) da cidade. Além desses, participaram 100 servidores públicos, usuários da modalidade de transporte individual, totalizando 530 respondentes.

\section{Resultados}

Os dados foram analisados com auxílio do software Excel e estão apresentados em três etapas: a) percepção dos taxistas; b) percepção dos mototaxistas; c) percepção de usuários.

\section{Percepção de taxistas sobre o aplicativo UBER}

A cidade conta com o universo de 125 taxistas cadastrados. Durante a coleta em nove praças de taxi: Mercado do Produtor, Rodoviaria, Hotel Raport, Correios, Santiago Maior, Avenida Adolfo Viana, Praça da Misericórdia, Hotel Orla, Hotel Rio Center, foram abordados 85 taxistas. Desses, 15 não aceitaram participar da pesquisa, totalizando 70 respondentes, conforme resultados apresentados na tabela 1.

Tabela 1 - Percepção de taxistas sobre o UBER

\begin{tabular}{l|c|c|c}
\multicolumn{1}{c|}{ Item } & Sim & Não & Não sei \\
\hline Conhece o aplicativo UBER. & $79 \%$ & $21 \%$ & $0 \%$ \\
\hline $\begin{array}{l}\text { Conhece e concorda com o modelo de transporte. } \\
\begin{array}{l}\text { Acreditam que os taxistas de Juazeiro aceitariam a } \\
\text { modalidade. }\end{array}\end{array}$ & $0 \%$ & $100 \%$ & $0 \%$ \\
\hline
\end{tabular}


Id on Line Revista Multidisciplinar e de Psicoloqia

Id on Line Multidisciplinary and Psycology Journal

Acredita que há taxista suficiente para atender ao público de Juazeiro.

Acredita que os taxis oferecem conforto e segurança aos clientes.

Concorda que há espaço para o aplicativo UBER em Juazeiro.

Você investiria recursos na modernização do atendimento aos clientes

Participaria de mobilização organizada por taxistas, contra o aplicativo, se for o caso.

O aplicativo em Juazeiro diminuiria a clientela dos taxistas.

Deixaria de ser taxista para ser UBER.

Fonte: dados da pesquisa (2017)

Dos 70 respondentes, a maioria afirmou conhecer o aplicativo UBER, bem como entendeu que a possível chegada do aplicativo na cidade de Juazeiro-BA não iria diminuir a clientela dos taxistas. Contudo, indagados quanto à existência de espaço, na cidade, para motoristas credenciados à Plataforma UBER, a maioria avaliou negativamente, corroborando os achados de pesquisas anteriores sobre a temática (OLMOS; FAVERA, 2016).

Sobre a possibilidade de o grupo participar de movimentos sociais contra a implantação do aplicativo, na cidade de Juazeiro, todos os respondentes atribuíram respostas afirmativas, inferindo, a partir dos resultados, que a concorrência já preocupa o grupo pesquisado. A partir da percepção do grupo, o taxi oferece conforto e segurança (100\%), contudo mais de $40 \%$ dos respondentes informaram que trocariam o taxi pelo UBER.

\section{Percepção de mototaxistas sobre o aplicativo UBER}

$\mathrm{O}$ instrumento de pesquisa foi entregue a 400 mototaxistas do universo de 700 cadastrados no município de Juazeiro-BA. Desses, 40 não responderam aos itens, totalizando 360 respondentes, conforme dados da tabela 2. 
Tabela 2 - Percepção de mototaxistas sobre o UBER

\begin{tabular}{|c|c|c|c|}
\hline Questões & Sim & Não & $\begin{array}{l}\text { Não } \\
\text { sei }\end{array}$ \\
\hline Conhece o aplicativo UBER. & $33 \%$ & $67 \%$ & $0 \%$ \\
\hline Conhece e concorda com o modelo de transporte. & $0 \%$ & $100 \%$ & $0 \%$ \\
\hline $\begin{array}{l}\text { Acreditam que os mototaxistas de Juazeiro aceitariam a } \\
\text { modalidade. }\end{array}$ & $36 \%$ & $64 \%$ & $0 \%$ \\
\hline $\begin{array}{l}\text { Acredita que há mototaxista suficientes para atender ao público de } \\
\text { Juazeiro. }\end{array}$ & $36 \%$ & $64 \%$ & $0 \%$ \\
\hline $\begin{array}{l}\text { Acredita que os mototaxis oferecem conforto e segurança aos } \\
\text { clientes. }\end{array}$ & $36 \%$ & $64 \%$ & $0 \%$ \\
\hline Concorda que há espaço para o aplicativo UBER em Juazeiro. & $0 \%$ & $64 \%$ & $36 \%$ \\
\hline $\begin{array}{l}\text { Você investiria recursos na modernização do atendimento aos } \\
\text { clientes }\end{array}$ & $0 \%$ & $64 \%$ & $36 \%$ \\
\hline $\begin{array}{l}\text { Participaria de mobilização organizada por moto taxistas, contra o } \\
\text { aplicativo, se for o caso. }\end{array}$ & $33 \%$ & $31 \%$ & $36 \%$ \\
\hline O aplicativo em Juazeiro diminuiria a clientela dos mototaxistas. & $36 \%$ & $64 \%$ & $0 \%$ \\
\hline Deixaria de ser moto taxista para ser UBER. & $64 \%$ & $36 \%$ & $0 \%$ \\
\hline
\end{tabular}

Fonte: Dados da pesquisa (2017)

Da mesma forma que os taxistas, os mototaxistas afirma conhecer e concordar com a modalidade de transporte, porém a maioria não conhece o aplicativo. Ao contrário da avaliação por taxistas, a maioria dos mototaxistas (64\%) atribuiu resposta favorável ao aplicativo UBER, inferindo, a partir dos respondentes, que a modalidade de transporte já se tornou atrativo para o grupo pesquisado. Isso talvez em função da eficiência dos serviços da nova modalidade (VIEGAS; LETRA, 2016) contrapondo a ausência de conforto e segurança no serviço de mototaxi.

\section{Percepção de usuários sobre o aplicativo UBER}

Para viabilizar a pesquisa com usuários de transporte individual, foram abordados servidores públicos municipais da cidade pesquisada, incluindo o setor de transporte urbano, obtendo o total de 100 respondentes para as questões sobre o aplicativo UBER, conforme demonstrado na tabela 3. 
Tabela 3 - Percepção de usuários sobre o UBER

\begin{tabular}{l|l|l|l}
\hline Questões & Sim & Não & $\begin{array}{l}\text { Não } \\
\text { sei }\end{array}$ \\
\hline $\begin{array}{l}\text { Conhece o aplicativo UBER. } \\
\text { Caso o aplicativo fosse adotado em Juazeiro, você o }\end{array}$ & $35 \%$ & $65 \%$ & $0 \%$ \\
\hline $\begin{array}{l}\text { usaria. } \\
\text { Daria preferência ao aplicativo UBER em relação aos } \\
\text { demais serviços de transporte }\end{array}$ & $60 \%$ & $40 \%$ & $0 \%$ \\
\hline Juazeiro comporta esse serviço de mobilidade urbana. & $35 \%$ & $40 \%$ & $25 \%$ \\
\hline
\end{tabular}

Fonte: Dados da pesquisa (2017)

A partir dos resultados, percebe-se que ainda há pouco conhecimento, por parte dos usuários, sobre a nova modalidade de transporte, mas, em contrapartida, a maioria dos respondentes (60\%) afirmou que usaria a aplicativo, opção que desperta o interesse da população em muitas cidades.

\section{Considerações Finais}

No contexto da mobilidade urbana, este estudo situou as modalidades de transporte mais utilizadas na cidade de Juazeiro-BA, enfatizando a mais recente opção de uso associado à tecnologia, no Brasil e no mundo: o UBER como forma de melhorar a acessibilidade e a mobilidade das pessoas.

Cumprindo o objetivo da pesquisa, buscou-se a identificar a percepção de taxistas, mototaxistas e usuários acerca do aplicativo, bem como a avaliação destes públicos sobre possível uso do meio de transporte, caso a empresa contemple o município pesquisado.

Resultados indicam que o quantitativo de taxistas cadastrados bem como o de mototaxistas ainda não atende plenamente a demanda da cidade e apontam, a partir da percepção dos respondentes (taxistas e mototaxistas), que a chegada do UBER não causaria prejuízos para as modalidades já existentes, mas que não há espaço, na cidade, para tal inovação, convergindo para os achados na literatura sobre o assunto, englobando demandas de direito e conflitos entre grupos de interesse. 
Tendo em vista a existência de reclamações, na mídia, acerca de atendimento inadequado ao usuário do transporte público, buscou-se, também, identificar a avaliação de usuários sobre o sistema UBER como alternativa de transporte em relação aos outros meios, inferindo, a partir dos resultados, que há pouco conhecimento, por parte desses respondentes, sobre a inovação tecnológica associada ao transporte e suas implicações no que tange ao conforto, rapidez e segurança. No entanto, esse público demonstra interesse em ter acesso à nova modalidade de locomoção urbana, modalidade atrativa também para o público mototaxista que cogita a possibilidade de passar a ser UBER.

Recomenda-se, como ampliação deste estudo, contemplar outros grupos de interesse, a exemplo de gestores e autoridades políticas para analisar a viabilidade de implantação do serviço pela plataforma UBER. Em que pese a limitações do método, resultados contribuem para o debate sobre novas formas de transporte e para a implantação de políticas de mobilidade urbana.

\section{Referências}

BRASIL. Lei 12.587, de 03 de janeiro de 2012. Institui as diretrizes da Política Nacional de Mobilidade Urbana. Disponível em: http://www.planalto.gov.br/ccivil_03/_ato20112014/2012/lei/112587.htm. Acesso em: 01 mar. 2017.

Brasil. Lei no 12.468, de 26 de agosto de 2011.Regulamenta a profissão de taxista. Disponível em: http://www.planalto.gov.br/ccivil_03/_Ato2011-2014/2011/Lei/L12468.htm. Acesso em: 20 ago. 2017.

FAVERA, Rafaela Bolson Dalla; OLMOS, Olívia Martins de Quadros. A polêmica em torno do aplicativo UBER no Brasil: Argumentos de direito contra e a favor da sua manutenção. In: VI Seminário Nacional Demandas Sociais e Políticas Públicas na sociedade contemporânea. Santa Catarina, 2016.

FREITAS NETO, J. T. et al. Óbitos Decorrentes de Acidentes de Trânsito Ocorridos em Petrolina-PE entre os anos 2010 a 2015: levantamento do perfil dos acidentados. In: I Seminário de Integração do PROFIAP/Univasf, Petrolina, 2017.

GOMIDE, Alexandre de Ávila; CARVALHO, Carlos Henrique. Transformações e tendências recentes na regulação dos serviços de ônibus urbano no brasil. Livraria Ipea, 2016. Disponível em: 〈http://repositorio.ipea.gov.br/bitstream/11058/6611/1/td_2187.pdf>. Acesso em: 19 fev. 2017. 
HAIR JR, Joseph F. et al. Fundamentos de métodos de pesquisa em administração. Porto Alegre: Bookman, 2005, 471 p.

MARCONI, M. A; LAKATOS, E. Maria. Fundamentos de Metodologia Científica. 7. São Paulo: Atlas, 2010.

MONTEIRO, Renato Leite. Proibição da Uber: a inconstitucionalidade do PL 349/2014 do município de São Paulo. Migalhas, 2015. Disponível em: $<$ http://www.migalhas.com.br/dePeso/16,MI223011,41046-

Proibicao+da+Uber+a+inconstitucionalidade+do+PL+3492014+do+Municipio>. Acesso em: 19 fev. 2017.

NUNES, Amanda. Um conceito através da exclusão: a legalidade da Uber. UFSC, Florianópolis, 2015.

O GLOBO. Conheça as diferenças entre o Uber e os táxis. Disponível em: $<$ http://infograficos.oglobo.globo.com/rio/conheca-as-diferencas-entre-o-uber-e-ostaxis.html>. Acesso em 19 de fevereiro de 2017.

UBER. Disponível em: <https://www.uber.com/>. Acesso em: 10 jan. 2017.

VASCONCELLOS, Eduardo Alcântara de. Mobilidade cotidiana, segregação urbana e exclusão. In: BALBIM, Renato; KRAUSE, Cleandro ; LINKE, Clarisse Cunha (orgs.). Cidade e movimento : mobilidades e interações no desenvolvimento urbano. Brasília : Ipea : ITDP, 2016. 326 p.

VIEGAS, Cláudia Mara de Almeida; LETRA, Luís Henrique Vasconcelos da Silva. A licitude dos serviços de transporte prestados pelo aplicativo UBER. Revista Cadernos do Programa de Pós-Graduação em Direito PPGDir./UFRGS, Porto alegre,v. 11, n. 1, 2016. Disponível em: 〈http://seer.ufrgs.br/index.php/ppgdir/article/view/61921/38151>. Acesso em: $11 \mathrm{mar}$. 2017.

Como citar este artigo (Formato ABNT):

FERREIRA, José S.; ALVES, Mariene A.; AQUINO, Mayara L.; RODRIGUES, Luzia C.; DUARTE, Francisco R. O Aplicativo Uber é uma tendência nas pequenas cidades como nova opção de Mobilidade Urbana. Id on Line Revista Multidisciplinar e de Psicologia, 2017, vol.11, n.37, p. 348-359. ISSN: 1981-1179.

Recebido: 26.08.2017

Aceito: 29.08 .2017 